\title{
Editorial
}

\section{Tackling education issues and maintaining professional training during pandemic}

\author{
Pallavi Ahluwalia ${ }^{1, *}$ \\ ${ }^{1}$ Dept. of Anaesthesia, Teerthanker Mahaveer Medical College and Research Hospital, Moradabad, Uttar Pradesh, India
}

\section{A R T I C L E I N F O}

Article history:

Received 05-09-2020

Accepted 06-09-2020

Available online 08-09-2020

Keywords:

Teleteaching

Online learning

Anaesthesia training

\begin{abstract}
A B S T R A C T
Current pandemic has given us an opportunity to evolve and adopt newer options to improve education. Tele-teaching by utilizing video conferencing and other interactive avenues has helped us maintain continuity of teaching curriculum. A major concern is-can lectures be substituted by online class? After pandemic both online and traditional learning will go hand in hand.
\end{abstract}

(C) 2020 Published by Innovative Publication. This is an open access article under the CC BY-NC license (https://creativecommons.org/licenses/by-nc/4.0/)
1.

Current pandemic has forced us to explore alternative ways to achieve our dreams. Past experiences testify that crisis motivates us to innovate and learn new things. Tele teaching and online trainings are innovative methods to meet the current needs. Pandemic has changed our viewpoint on education. We have seen a surge in e-learning /online learning during pandemic. Tele-education by definition means the use of information and communication technologies (ICT) to improve knowledge and enhance performance. ${ }^{1}$ Distant learning was always there (in the background) since many years. The idea was to utilize idle time and learn new knowledge to enhance clinical skills and improve clinical judgments. Current pandemic has glorified online learning and we have seen exponential rise in number of online programs. Over the time online teaching has evolved exponentially, to meet the demands of modern era. Despite few shortcomings, it's a cost effective and efficient education tool compared to traditional teaching if used wisely. There are certain advantages of online teaching. Research has shown that there is increased retention of the topic and lesser time is consumed. ${ }^{2}$ Drawbacks include

\footnotetext{
* Corresponding author.

E-mail address: drpallaviahluwalia@yahoo.com (P. Ahluwalia).
}

lack of training, insufficient band width, little preparation and poor user experience. Students need a structured environment to learn and they get easily distracted during online learning. Hasty transition to online learning may have long term impact on critical thinking and adaptability. A valid question arises- whether online learning will continue post pandemic? What is interpreted is that a Hybrid model of education will emerge and online education will become integral part of institutions. Traditional and online will go hand in hand after pandemic.

Across the world, Anaesthetists are playing frontline roles in fight against COVID 19. They are working tirelessly in managing patients on ventilators, in ICU's. Many were motivated to make meaningful contribution to educate others by online teaching in the form of webinars, online tutorials and lectures. A variety of webinars are being conducted using video conferencing (Zoom Video Communications) or interactive television, audio conferencing, video-sharing, etc. Computer assisted learning means any learning that is mediated by computer but doesn't require any direct interaction between the user and instructor (human) in order to run. Tele-education plays an important role in addressing professional isolation, frequently experienced by health care professionals located in remote and rural areas. A new generation of web-based 
tools such as wikis, blogs and podcasts are promising options to collaborate clinical practice and education. Wikis are websites and can be edited, if access is granted. 'Blog' means a 'web log'- means an online web journal and is a source of rich multimedia environment. Podcasts are a collection of audio and video materials and doesn't require user intervention. Advantage is anytime, anywhere learning as the files can be downloaded, to be accessed later.

Traditionally, anaesthesia training involved didactic lectures, simulation workshops and skill demonstration on patients. In our setup, to maintain continuity, a schedule of online lectures and tutorials was made. The tutorials were predominantly delivered by trainees. Some topics were taught by consultants. We tried to match the topics to their clinical experience and expertise. We even requested a post tutorial feedback to improve further online tutorials. Inputs were considered and amendments were done accordingly. We noticed lack of social contact amongst students, which normally would have occurred between tutorials. To overcome this we tried to continue session (for few minutes), after the presenter had left and give them some time for clearing doubts and discussion. For few lengthy topics, a pre-tutorial material was posted so that all important points could be covered in same sitting. We observed that interaction improved over time and students were more comfortable with Tele -teaching. We uploaded few pre-recorded online tutorials and videos for trainees, which they could access anytime, to improve their understanding about a particular topic. Time to attend live tutorials was allocated away from clinical work and attendance was recorded. From our past experiences, we found that the motivation to engage with online learning is predominantly influenced not by external factors but by interest, control, and freedom of choice, ${ }^{3}$ so we adopted all these features and modified our approach. Few issues like maintaining standards of training and whether these virtual classes can substitute classroom training are still a cause of concern. Social media and online sharing play a major role in dissipating knowledge. We sincerely hope that we are able to restart face-to face tutorials as soon as possible, but we are happy that we could continue our anaesthetic training successfully during pandemic by adopting Tele-teaching. In future also, we predict an increasing role of online education as a supplement to traditional teaching. This will allow greater flexibility and will hopefully increase engagement. Since online medical resources are freely accessible and with technology-enhanced learning, ${ }^{4,5}$ we are confident that our resources and data base will continue to evolve and we will be able to make substantial contributions in anaesthesia training. Lastly as a clinician, Tele-consultation is an important means to reach out to the patients who cannot come to hospital like patients needing palliative care. We are happy that we could rapidly deploy audio, video and computer technologies to reach our patients.

\section{Conflict of Interest}

Nil.

\section{References}

1. Masic I. E-Learning as New Method of Medical Education. Acta Inform Med. 2008;16(2):102-17.

2. Li C, Lalani F. The COVID-19 pandemic has changed education forever. Available from: https://www.weforum.org/agenda/2020/04/ coronaviruseducation-global-covid19-online-digital-learning/.

3. Song D, Bonk CJ. Motivational factors in self-directed informal learning from online learning resources. Cogent Educ. 2016;3(1):1-11.

4. Carroll CL, Bruno K, vonTschudi M. Social Media and Free Open Access Medical Education: The Future of Medical and Nursing Education? Am J Crit Care. 2016;25(1):93-6.

5. Wang JJ, Deng A, Tsui BCH. COVID-19: novel pandemic, novel generation of medical students. Br J Anaesth. 2020;125(3):e328-30.

\section{Author biography}

Pallavi Ahluwalia Professor

Cite this article: Ahluwalia P. Tackling education issues and maintaining professional training during pandemic. Indian J Clin Anaesth 2020;7(3):367-368. 